\title{
GSTM1 polymorphism in patients with primary open-angle glaucoma
}

\author{
A.M. Barbosa ${ }^{1}$, A.B. Frare ${ }^{2,3}$, N.B. Costa ${ }^{2,3}$, R.E. Silva ${ }^{4}$ and \\ K.K.V.O. Moura ${ }^{5}$ \\ ${ }^{1}$ Curso de Biologia, Pontifícia Universidade Católica de Goiás, \\ Goiânia, GO, Brasil \\ ${ }^{2}$ Núcleo de Pesquisa Replicon, Pontifícia Universidade Católica de Goiás, \\ Goiânia, GO, Brasil \\ ${ }^{3}$ Programa de Pós-Gradução em Genética, Pontifícia Universidade Católica de Goiás, \\ Goiânia, GO, Brasil \\ ${ }^{4}$ Clínica VER, Goiânia, GO, Brasil \\ ${ }_{5}^{5}$ Departamento de Biomedicina, Pontifícia Universidade Católica de Goiás, \\ Goiânia, GO, Brasil
}

Corresponding authors: A.M. Barbosa / K.K.V.O. Moura

E-mail: andreiamarcelino_@hotmail.com / kkverolli@pucgoias.edu.br

Genet. Mol. Res. 11 (3): 3256-3262 (2012)

Received November 4, 2011

Accepted June 4, 2012

Published September 12, 2012

DOI http://dx.doi.org/10.4238/2012.September.12.8

\begin{abstract}
Primary open-angle glaucoma (POAG) is characterized by loss of retinal ganglion cells, optic nerve damage and irreversible loss of visual field. Glaucoma is the second leading cause of blindness worldwide. It was estimated that in 2010 there were about 60.5 million glaucoma cases worldwide; among these patients, 4.5 million will become bilaterally blind. Glutathione S-transferases (GST) are a group of drug-metabolizing enzymes of phase-II that act in the detoxification of xenobiotics and inactivate end-products formed as secondary metabolites during oxidative stress. Through PCR amplification, we analyzed the GSTM1 gene in DNA samples from 25 patients with POAG and 25 controls; 14 of the patients presented the GSTM1 gene null polymorphism while only eight of the control group had this gene.
\end{abstract}


Although the POAG patients had a higher frequency of GSTM1, the difference was not significant $(\mathrm{P}=0.0874)$; this lack of significance could be due to the small sample size.

Key words: Primary open-angle glaucoma; Polymorphism; GSTM1

\section{INTRODUCTION}

Glaucoma is a progressive disease characterized by the apoptosis of retinal ganglion cells. This process causes excavation of the optic nerve head, visual field loss, and eventual blindness (Quigley et al., 1995). Glaucoma is an ocular neuropathy characterized by a specific pattern of damage to the optic nerve disk and visual field. This damage is the result of various socioenvironmental conditions that can affect the eye (Ritch et al., 1996). Regardless of the pathophysiology, the damage to the disk of the optic nerve is similar, with loss of neural tissue gradually leading to the appearance of lesions, which are a common characteristic of glaucoma with visual field defects that lead to blindness (Wiggs, 2007). The disease is present in all ethnic groups, but is more prevalent in Asians and more harmful in Africans or individuals of African descent (Racette et al., 2003). It affects individuals at all ages but is more common among those aged $\geq 40$ years, affecting 1 in 100 people older than 40 years (Dias and Almeida, 2000).

The pathophysiology of glaucoma is not fully understood, because several structures are involved. These structures include the aqueous humor, the trabecular meshwork, the Schlemm canal, and the optic nerve itself. The main risk factor for glaucoma is increased intraocular pressure (IOP), which is in most cases due to increased resistance to the outflow of aqueous humor through the trabecular meshwork, which also leads to optic nerve damage (Juronen et al., 2000). Several factors seem to contribute to the appearance of this symptom, although they appear in varying degrees. Increased IOP is still considered by many researchers to be the main risk factor for the disease because: 1) glaucoma often develops in eyes with IOP above the normal level $(23-26 \mathrm{mmHg}), 2)$ IOP is the only risk factor that can easily be measured and treated, and 3) the normalization of IOP usually delays or stops the evolution of glaucoma. Nevertheless, resistance to the development of glaucoma demonstrated by some individuals with ocular hypertension and the apparent occurrence of glaucoma in rare individuals with normal or slightly above the normal IOP (normal-tension glaucoma) shows that IOP is not the only significant factor for the disease. Tolerance to a certain IOP contributes to individual variation in the disease, and other factors such as increased ocular peripheral vascular resistance, reduction of blood flow to the optic nerve, the action of excitotoxins, and depletion of neurotrophins in the retinal ganglion cells can interfere, increasing predisposition to glaucoma or triggering it (Marigo et al., 2001). Several reports implicate genetic factors in the etiology of glaucoma; the condition is usually seen in related individuals and specific ethnic groups, often associated with consanguinity in affected families (Sarfarazi et al, 1995).

Glaucoma is the second leading cause of blindness worldwide. In 2010, 60.5 million glaucoma cases were estimated worldwide, and among them, 4.5 million were cases of primary open-angle glaucoma (POAG), and 3.9 million POAG patients were bilaterally blind (Quigley and Broman, 2006). Approximately 900,000 disease carriers live in Brazil. Alarmingly, 720,000 are likely asymptomatic, and many of them require diagnosis as early as possible so that their quality of life is not compromised and blindness can be avoided ( $2^{\circ}$ Consenso Brasileiro de Glau- 
coma Primário de Ângulo Aberto). Owing to variations in the pathophysiology, clinical presentation, and treatment of the various types of glaucoma, a uniform classification that covers all forms of this disease does not exist. However, we can classify glaucoma as congenital or acquired if it is present from birth or after 2 years of age, respectively; as open or closed angle, based on the mechanism of aqueous humor flow drainage reduction, and as primary and secondary, depending on the presence or absence of factors increasing IOP (Kanski, 2003). Glaucoma can also be classified according to etiology (primary or secondary), anatomy of the camerular sinus (open or closed angle), IOP (IOP $\geq 21 \mathrm{mmHg}$, high-tension glaucoma; IOP $<21 \mathrm{mmHg}$, normal-tension glaucoma), or age of onset (congenital, juvenile, or adult; Leske, 1983).

POAG is characterized by loss of retinal ganglion cells, optic nerve damage, and irreversible visual field loss. The most prevalent type of glaucoma is POAG with high eye pressure, which is associated with increased IOP. Approximately one-third of patients with POAG have normal IOP, a condition called normal-tension glaucoma (Kamal and Hitchings, 1998). POAG is a complex and heterogeneous optic neuropathy that is estimated to affect 70 million people worldwide, making it the second leading cause of blindness in the developed world (Quigley, 1996). Recent studies have suggested oxidative stress caused by the accumulation of reactive oxygen species as a possible cause of POAG (Juronen et al., 2000).

Glutathione $S$-transferases (GSTs) are a group of drug-metabolizing phase II enzymes that detoxify endogenous electrophilic xenobiotics and inactivate end-products formed as secondary metabolites during oxidative stress. GSTs are present in various ocular structures, including the aqueous humor, ciliary body, and lens. Changes in the metabolic pathway, which involves the GSTM1, can form the toxic metabolites and can induce changes in the structure of proteins present in the aqueous humor and trabecular meshwork, reducing flow and increasing IOP (Izzotti et al., 2006). The GST isozymes expressed in human tissues include those of the alpha, mu, pi, theta, kappa, sigma, zeta, and omega gene families (Board et al., 1997). GSTM1, a member of the GSTM family of enzymes, detoxifies a variety of electrophilic substances, including carcinogens such as polycyclic aromatic hydrocarbons, ethylene oxide, styrene, and epoxides (Katoh et al., 2008). A lack of GSTM1 enzyme may impair the elimination of carcinogenic compounds from the body, increasing the risk of cancer (Rebbeck, 1997). This study aimed to detect the GSTM1 gene polymorphism in patients with POAG.

\section{PATIENTS AND METHODS}

This study analyzed 50 samples: 25 patients with POAG and 25 controls. The samples (10 mL peripheral blood) were collected at the Pronto Eye Clinic (Goiânia, Goiás) and were analyzed in the Research Center Replicon - PUC GO (Pontifícia Universidade Católica de Goiás). DNA was extracted from the samples using an Illustra ${ }^{\mathrm{TM}}$ Blood Genomic Spin Mini Prep Kit (GE Healthcare, UK).

The patients answered a questionnaire on smoking, drinking and family member blinded by glaucoma.

DNA integrity was certified through electrophoresis on $2 \%$ agarose gel stained with $0.5 \mathrm{mg} / \mathrm{mL}$ ethidium bromide and visualized with a VDS Video Documentation System ${ }^{\circledR}$ (Amersham Biosciences, USA). These samples were subsequently subjected to polymerase chain reaction (forward: 5'-GAA CTC CCT GAA AAG GCT AAA GC-3'; reverse: 5'-GTT GGG CTA AAT ATA CGG TGG-3') for analysis of the GSTM1 gene. Samples were taken in dupli- 
cate, and the gene $Z F X / Y$ was used as an internal control. Statistical analysis was performed using Bioestat 5.0, and the chi-square test and odds ratio were used.

\section{RESULTS}

We analyzed the genotype frequencies of the GSTM1 gene in patients with POAG (N $=25)$ and in the control group $(\mathrm{N}=25$; Table 1$)$. GSTM1 polymorphism was present in $56 \%$ $(14 / 25)$ and absent $44 \%(11 / 25)$ of patients with glaucoma. In the control group $(\mathrm{N}=25)$ the polymorphism was detected in $68 \%(17 / 25)$ and was absent in $32 \%(8 / 25)$. Only 49 of the subjects answered the questionnaire about social habits.

\begin{tabular}{|c|c|c|c|c|c|c|c|c|}
\hline \multirow[t]{2}{*}{ Variable } & \multicolumn{2}{|c|}{ Glaucoma } & \multicolumn{2}{|c|}{ Control } & \multirow[t]{2}{*}{$* \mathrm{P}$} & \multirow[t]{2}{*}{ Odds } & \multirow[t]{2}{*}{ Minimum } & \multirow[t]{2}{*}{ Maximum } \\
\hline & $\%$ & $\mathrm{~N}$ & $\%$ & $\mathrm{~N}$ & & & & \\
\hline GSTM1 & 56 & 14 & 32 & 8 & \multirow{3}{*}{0.0874} & & \multirow{3}{*}{0.8536} & \multirow{3}{*}{8.5686} \\
\hline GSTM1null & 44 & 11 & 68 & 17 & & 2.7045 & & \\
\hline Total & 100 & 25 & 100 & 25 & & $\mathrm{P}=0.1543$ & & \\
\hline
\end{tabular}

$* \mathrm{P}=$ chi-square test.

We analyzed a subgroup of POAG patients who claimed to consume alcoholic beverages $(\mathrm{N}=9)$ related to the GSTM1 polymorphism (Table 2$)$. The GSTM1 polymorphism was found in 44\% (4/9) and was absent in 56\% (5/9) of these patients. Among those in the control group who claimed to consume alcoholic beverages $(\mathrm{N}=9)$ the GSTM1 polymorphism was present in $44 \%$ (4/9) and absent in 56\% (5/9). The frequency of the polymorphism was equal in both groups of patients, so there was no statistically significant difference $(\mathrm{P}=1)$.

\begin{tabular}{|c|c|c|c|c|c|c|c|c|}
\hline \multirow[t]{2}{*}{ Variable } & \multicolumn{2}{|c|}{ Glaucoma } & \multicolumn{2}{|c|}{ Control } & \multirow[t]{2}{*}{$* \mathrm{P}$} & \multirow[t]{2}{*}{ Odds } & \multirow[t]{2}{*}{ Minimum } & \multirow[t]{2}{*}{ Maximum } \\
\hline & $\%$ & Yes & $\%$ & Yes & & & & \\
\hline GSTM1 & 44 & 4 & 44 & 4 & & & & \\
\hline GSTM1null & 56 & 5 & 56 & 5 & 1 & - & - & - \\
\hline \multirow[t]{2}{*}{ Total } & 100 & 9 & 100 & 9 & & & & \\
\hline & $\%$ & No & $\%$ & No & & & & \\
\hline GSTM1 & 67 & 10 & 25 & 4 & & & & \\
\hline GSTM1null & 33 & 5 & 75 & 12 & 0.0198 & 6.0000 & 1.2611 & 28.5476 \\
\hline Total & 100 & 15 & 100 & 16 & & $\mathrm{P}=0.0490$ & & \\
\hline
\end{tabular}

$* \mathrm{P}=$ chi-square test.

Of the patients in the control group who claimed to consume no alcohol, 25\% (4/16) displayed the GSTM1 polymorphism and 75\% (12/16) did not. The GSTM1 polymorphism was present in $67 \%(10 / 15)$ of glaucoma patients who claimed not to consume alcoholic beverages and absent in 33\% (5/15). The frequency of the GSTM1 polymorphism was 2.68 times higher in patients with glaucoma (67\%) than that in the control group (25\%), and this difference was statistically significant $(\mathrm{P}=0.0198)$. 
We analyzed smoking and the GSTM1 polymorphism among POAG patients and controls (Table 3). In the POAG group, 1 person claimed to smoke, and 23 denied smoking. All patients in the control group denied smoking. All patients in the POAG group who smoked $(100 \% ; 1 / 1)$ displayed the GSTM1 polymorphism.

\begin{tabular}{|c|c|c|c|c|c|c|c|c|}
\hline \multirow[t]{2}{*}{ Variable } & \multicolumn{2}{|c|}{ Glaucoma } & \multicolumn{2}{|c|}{ Control } & \multirow[t]{2}{*}{$* \mathrm{P}$} & \multirow[t]{2}{*}{ Odds } & \multirow[t]{2}{*}{ Minimum } & \multirow[t]{2}{*}{ Maximum } \\
\hline & $\%$ & Yes & $\%$ & Yes & & & & \\
\hline GSTM1 & 100 & 1 & - & - & & & & \\
\hline GSTM1null & - & - & - & - & - & - & - & - \\
\hline \multirow[t]{2}{*}{ Total } & 100 & 1 & 100 & - & & & & \\
\hline & $\%$ & No & $\%$ & No & & & & \\
\hline GSTM1 & 57 & 13 & 32 & 8 & & & & \\
\hline GSTM1null & 43 & 10 & 68 & 17 & 0.0871 & 2.7625 & 0.8512 & 8.9652 \\
\hline Total & 100 & 23 & 100 & 25 & & $\mathrm{P}=0.1557$ & & \\
\hline
\end{tabular}

$* \mathrm{P}=$ chi-square test.

In $32 \%(8 / 25)$ of the patients in the control group who denied smoking, the GSTM1 polymorphism was present, and it was absent in $68 \%(17 / 25)$. The GSTM1 polymorphism was detected in 57\% (13/23) of glaucoma patients who denied smoking and was absent in $43 \%$ $(10 / 23)$. In this subgroup, the frequency of the GSTM1 polymorphism was 1.78 times higher in patients with glaucoma (57\%) than that in the control group (32\%). However, this difference was not statistically significant $(\mathrm{P}=0.0871)$.

We analyzed a subgroup of patients with glaucoma who claimed to have family history of glaucoma $(\mathrm{N}=6)$ in relation to the GSTM1 polymorphism (1 patient did not complete the questionnaire; Table 4). Sixty-seven percent (4/6) displayed the GSTM1 polymorphism, and it was absent in $33 \%(2 / 6)$. Among those in the control group who claimed to have family history of glaucoma ( $=7)$, the GSTM1 polymorphism was present in $29 \%(2 / 7)$ and absent in $71 \%(5 / 7)$. The frequency of the GSTM1 polymorphism was twice as high (2.31) in patients with glaucoma who confirmed family history of glaucoma as that in controls. However, this difference was not statistically significant $(\mathrm{P}=0.1696)$.

\begin{tabular}{|c|c|c|c|c|c|c|c|c|}
\hline \multirow[t]{2}{*}{ Variable } & \multicolumn{2}{|c|}{ Glaucoma } & \multicolumn{2}{|c|}{ Control } & \multirow[t]{2}{*}{$* \mathrm{P}$} & \multirow[t]{2}{*}{ Odds } & \multirow[t]{2}{*}{ Minimum } & \multirow[t]{2}{*}{ Maximum } \\
\hline & $\%$ & Yes & $\%$ & Yes & & & & \\
\hline GSTM1 & 67 & 4 & 29 & 2 & \multirow{3}{*}{0,1696} & & \multirow{3}{*}{ - } & \\
\hline GSTM1null & 33 & 2 & 71 & 5 & & 5.0000 & & - \\
\hline \multirow[t]{2}{*}{ Total } & 100 & 6 & 100 & 7 & & $\mathrm{P}=0.4148$ & & \\
\hline & $\%$ & No & $\%$ & No & & & & \\
\hline GSTM1 & 59 & 10 & 35 & 6 & & & & \\
\hline GSTM1null & 41 & 7 & 65 & 11 & 0,1693 & 2.6190 & 0.6546 & 10.4787 \\
\hline Total & 100 & 17 & 100 & 17 & & $\mathrm{P}=0.3026$ & & \\
\hline
\end{tabular}

$* \mathrm{P}=$ chi-square test. 
Among patients in the control group who claimed to have no family history of glaucoma $(\mathrm{N}=17)$, the GSTM1 polymorphism was present in $35 \%(6 / 17)$ and absent in $65 \%$ (11/17). Of the glaucoma patients who claimed to have no family history of glaucoma $(\mathrm{N}=$ 17) the presence of the GSTM1 polymorphism was detected in 59\% (10/17) and absent $41 \%$ (7/17). The frequency of polymorphism was approximately 1.7 times higher in the group of patients with glaucoma (59\%) than that in the control group (35\%). However, this difference was not statistically significant $(\mathrm{P}=0.1693)$.

\section{DISCUSSION}

A large number of studies have attempted to demonstrate a link between susceptibility to POAG and polymorphic variants in GST genes. In addition, some studies have emphasized the association between GST polymorphisms and risk of eye diseases, including cataracts, senile macular degeneration, and glaucoma (Unal et al., 2007). The present study found a higher frequency of the GSTM1 null genotype in the control group $(68 \%)$ than in the glaucoma group (44\%), and our data corroborate those of Unal et al. (2007), in which a higher frequency of the GSTM1 null genotype was found in the control group (45\%) than in the glaucoma group (21.5\%). Unal et al. (2007) analyzed 144 patients with POAG and 121 controls implementing the sequence of primers used in our study. Other studies, such as that of Abu-Amero (2008), have analyzed the probable connection between smoking and POAG and, similar to the outcome our study, found no significant relationship. He studied 107 patients, 49 of them had POAG.

We found no connection between glaucoma and positive family history of glaucoma. However, Uhm and Shin (1992) have described a significant relationship between patients with POAG and family history of glaucoma. These researchers analyzed 361 patients with POAG and found a $27.15 \%(98 / 361)$ prevalence of positive family history for POAG.

The number of patients diagnosed with glaucoma is growing, which raises the need for greater intervention. Health agencies and providers should promote public awareness and the possibility of new studies and treatments that can provide innovative responses to this illness.

We can conclude from our study that no statistical significance exists in the GSTM1 polymorphism in patients who claimed to consume alcoholic beverages, smoke, and have a family history of glaucoma and family members who were blinded by glaucoma. However, we found significant results among patients who denied use of alcoholic beverages.

\section{ACKNOWLEDGMENTS}

A.M. Barbosa thanks Fundação de Amparo à Pesquisa do Estado de Goiás (FAPEG) for financial support.

\section{REFERENCES}

Abu-Amero KK, Morales J, Mohamed GH, Osman MN, et al. (2008). Glutathione S-transferase M1 and T1 polymorphisms in Arab glaucoma patients. Mol. Vis. 14: 425-430.

Board PG, Baker RT, Chelvanayagam G and Jermiin LS (1997). Zeta, a novel class of glutathione transferases in a range of species from plants to humans. Biochem. J. 328: 929-935. 
Dias JFP and Almeida HG (2000). Glaucoma. $2^{\text {a }}$ ed. Cultura Médica, Rio de Janeiro.

Izzotti A, Bagnis A and Sacca SC (2006). The role of oxidative stress in glaucoma. Mutat. Res. 612: 105-114.

Juronen E, Tasa G, Veromann S, Parts L, et al. (2000). Polymorphic glutathione S-transferase M1 is a risk factor of primary open-angle glaucoma among Estonians. Exp. Eye Res. 71: 447-452.

Kamal D and Hitchings R (1998). Normal tension glaucoma - a practical approach. Br. J. Ophthalmol. 82: 835-840.

Kanski JJ (2003). Oftalmologia Clínica: Uma Abordagem Sistemática. $5^{\text {a }}$ ed. Elsevier, Rio de Janeiro.

Katoh T, Yamano Y, Tsuji M and Watanabe M (2008). Genetic polymorphisms of human cytosol glutathione S-transferases and prostate cancer. Pharmacogenomics 9: 93-104.

Leske MC (1983). The epidemiology of open-angle glaucoma: a review. Am. J. Epidemiol. 118: 166-191.

Marigo FA, Cronemberger S and Calixto N (2001). Neuroproteção: situação atual no glaucoma. Arq. Bras. Oftalmol. 64: 167-171.

Quigley HA (1996). Number of people with glaucoma worldwide. Br. J. Ophthalmol. 80: 389-393.

Quigley HA and Broman AT (2006). The number of people with glaucoma worldwide in 2010 and 2020. Br. J. Ophthalmol. 90: 262-267.

Quigley HA, Nickells RW, Kerrigan LA, Pease ME, et al. (1995). Retinal ganglion cell death in experimental glaucoma and after axotomy occurs by apoptosis. Invest. Ophthalmol. Vis. Sci. 36: 774-786.

Racette L, Wilson MR, Zangwill LM, Weinreb RN, et al. (2003). Primary open-angle glaucoma in blacks: a review. Surv. Ophthalmol. 48: 295-313.

Rebbeck TR (1997). Molecular epidemiology of the human glutathione S-transferase genotypes GSTM1 and GSTT1 in cancer susceptibility. Cancer Epidemiol. Biomarkers Prev. 6: 733-743.

Ritch R, Shields MB and Krupin T (1996). The Glaucomas. Basic Sciences Vol. 1. 2nd edn. Mosby - Year Book, St. Louis.

Sarfarazi M, Akarsu AN, Hossain A, Turacli ME, et al. (1995). Assignment of a locus (GLC3A) for primary congenital glaucoma (Buphthalmos) to 2p21 and evidence for genetic heterogeneity. Genomics 30: 171-177.

Uhm KB and Shin DH (1992). Positive family history of glaucoma is a risk factor for increased IOP rather than glaucomatous optic nerve damage (POAG vs OH vs normal control). Korean J. Ophthalmol. 6: 100-104.

Unal M, Guven M, Devranoglu K, Ozaydin A, et al. (2007). Glutathione S transferase M1 and T1 genetic polymorphisms are related to the risk of primary open-angle glaucoma: a study in a Turkish population. Br. J. Ophthalmol. 91: 527-530.

Wiggs JL (2007). Genetic etiologies of glaucoma. Arch. Ophthalmol. 125: 30-37. 